\title{
創意學習交流理念的推廣
}

\section{Promotion of creative \\ learning exchange philosophy}

陳宗鈺

Chen , Tzong-Yue

\section{國立基隆女中圖書館主任 \\ Director of Library \\ National Keelung Girls’ Senior High School, Taiwan}

\begin{abstract}
Traditional approaches to organizational management focused on the analysis of individual problems and incremental change. In a modern society full of rapidly evolving science technology, what used to work seems no longer to suffice as schools continue to experience complex changes. It is becoming increasingly more difficult to see the consequences as a result of our decisions and to learn from experience. No longer can a person derive a sense of security and comfort from merely doing a day's work for a day's pay. Neither can an employee quietly pursue his or her job, while totally unconcerned about what other partners are doing. Sad to say, not much can be expected of today's school curricula to meet enterprises' requirements. This explains why a school library plays an important role in putting together the school's and local community's resources for the purpose of promoting readers creative learning exchange(CLE) concept, building in them a systematic thinking model and developing their capabilities in solving problems.
\end{abstract}

The procedure of promoting creative learning exchange philosophy in my school is as follows:

- Setting up readers' database and public relationship networking. It includes information on school administration staff, teachers、 students、 alumni and students' parents. It is also a good idea to recruit enthusiastic persons together to help promote the drive.

- Forming reading clubs among teachers, students、 students' parents and school administration staff. They are encouraged to read books and exchange views.

- Holding regular contests in web page design, book reading report and evaluation of reading club performance. It is hoped that improvements are made and problems are pinpointed and solved in the process.

- Compiling and editing CLE training materials and training seed teachers and students to learn to operate computer software tools. It is believed to be helpful to systematically and effectively promote CLE on a long-term basis.

- Publishing electronic newsletters for the local community. It is powerful for a media tool to be used in marketing creative learning exchange philosophy.

- Planning the school's specific future goals and establishing priority of unsolved problems. Organizing a team of creative learning exchange to solve problems by systematic thinking process. 


\section{Introduction Of System Thinking Tool: Vensim}

Vensim is a visual modeling tool that allows you to conceptualize, document, simulate, analyze, and optimize models of dynamic systems. Vensim provides a simple and flexible way of building simulation models from causal loop or stack and flow diagrams.

By connecting words with arrows, relationships among system variables are entered and recorded as causal connections. This information is used by the Equation Editor to help you form a complete simulation model. You can analyze your model throughout the building process, looking at the causes and uses of a variable, and also at the loops involving the variable. When you have built a model that can be simulated, Vensim lets you thoroughly explore the behavior of the model.

The following is a example of the population growth: As the figure 1, it is a causal loop of the population growth. Its left side is an increasing causal loop and right side is an adjusting causal loop.

Figure 1. Population Causal Loop

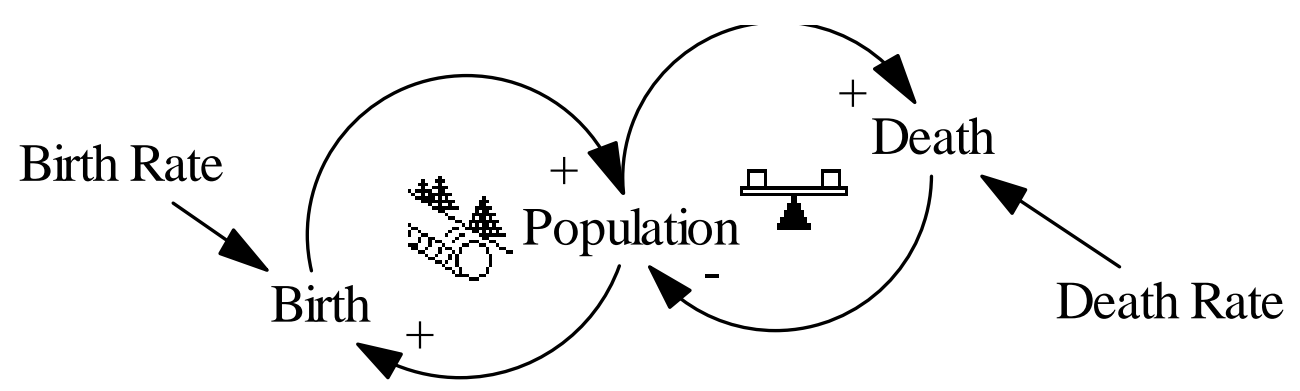

The figure 2 is a stack and flow diagram of population growth, its the initial population is 100,000 people, and their formula and units are as follow:

(1) "population" = INTEG("Birth"-"Death",100000) units: persons

(2) "Birth" = "Population" * "Birth Rate"

units: persons

(3) "Birth Rate" = 0.013

units: $1 /$ year

(4) "Death" = "Population" *

"Birth Rate"

(5) "Death Rate" $=0.008$

units: 1 /year

INTEG : Mathematics’ Integration Function

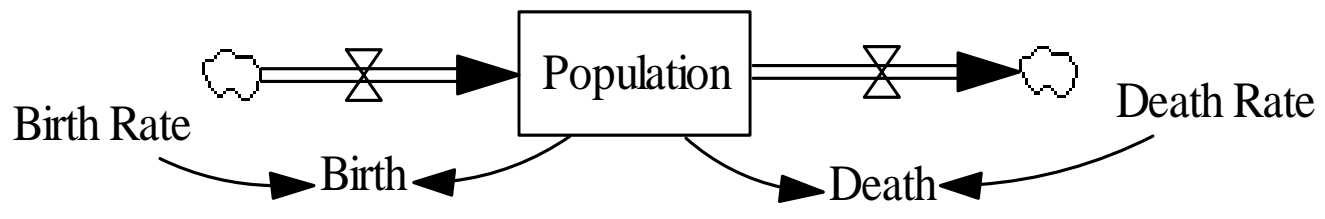

Figure 2. Population Stock and Flow Diagram 
Estimate in advance and simulate population's growth diagram, what is the population after five hundred years? Based on the figure 3, there are almost 1,200,000 people.

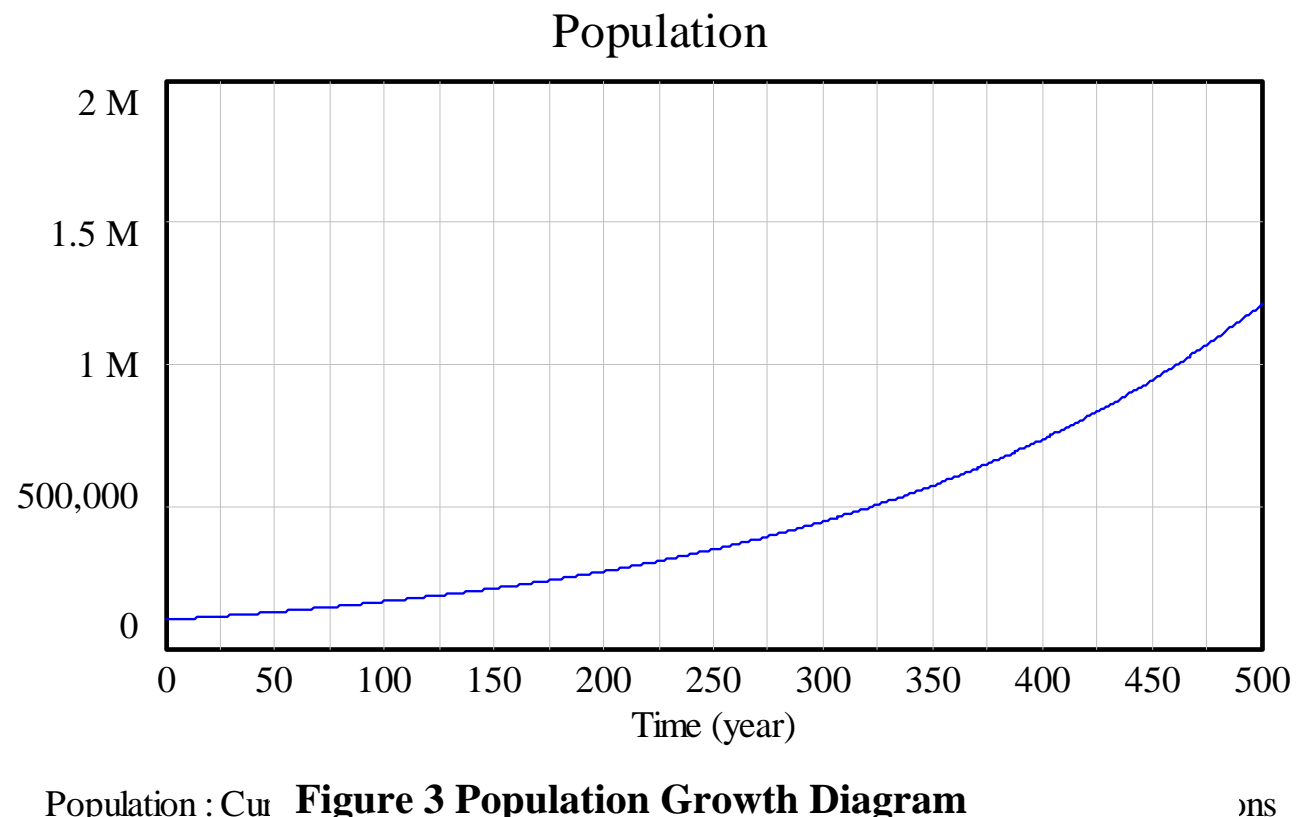

Revised model: In total population, women can bear children, only they have the ability to nurse a baby , according to the statistics report, during twenty six years nursing term, one woman can give birth to 1.42 children on average, so this will modify the model, the stack and flow diagram is as Figure 4, their formula and units are as follow:

(1) Nursing Female $=$ Population * 0.5

(2) Death Rate $=1 / 80$

Suppose one person has

Eighty years long life

In average,

Death Rate of every year

$=1$ /average life

(3) Birth Rate $=1.42 / 26 /$ year

(4) Birth $=$ Nursing Female $*$ Birth rate 


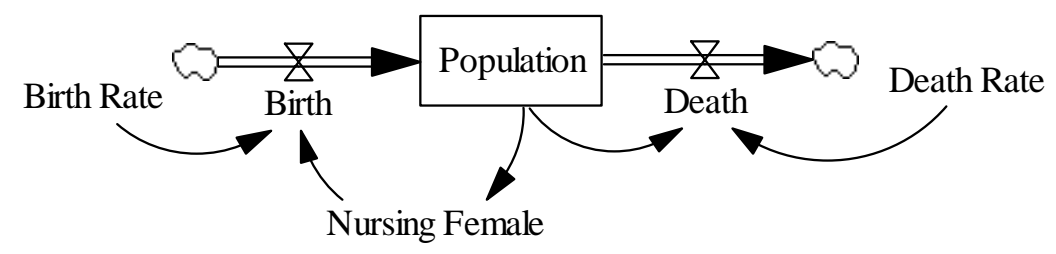

Figure 4. Revised Population Stock and Flow

Its population grow up situation: there are about 155,550,000 people after 500 years; If birth rate is $1 / 26$ on average every year, there are about 2,862,000 people after 500 years; So based on this figure 5, we can stipulate the population growth policy by controlling the birth rate.

Figure 5 Population Growth Diagram

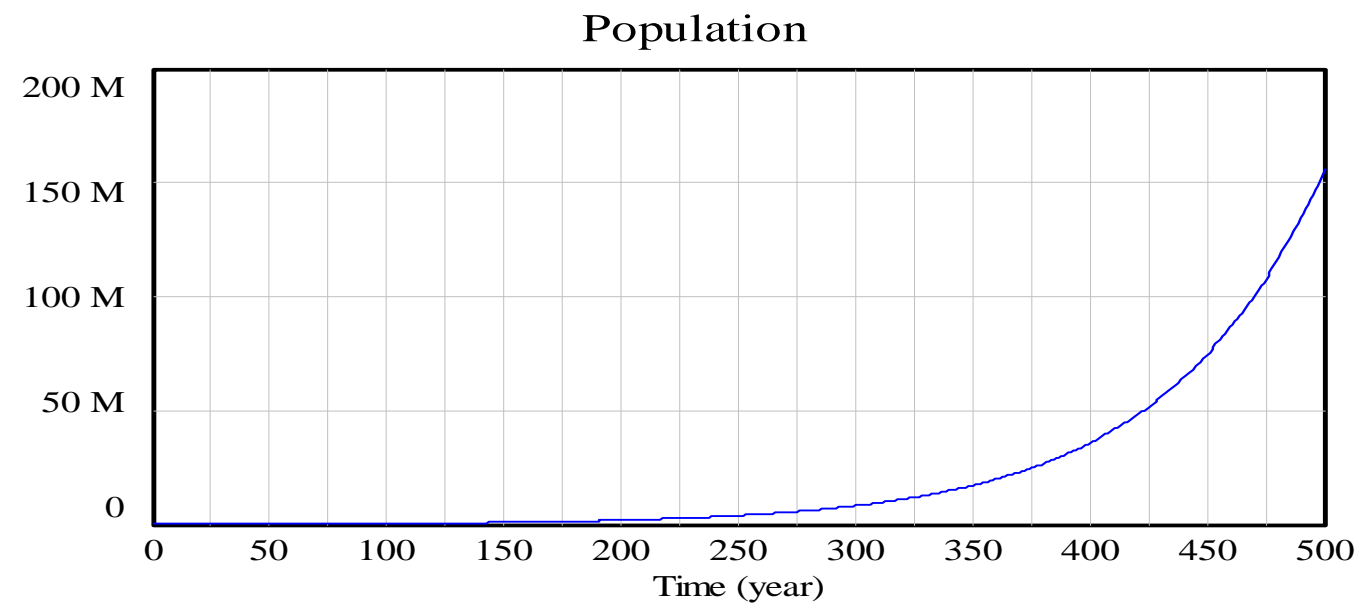

Population : Current persons 


\section{HOW TO ORGANIZE A LEARNING-ORIENTED SCHOOL}

In the process of creative learning, the classroom, the school and the community play their own specific roles yet work closely together, Only three systems change at the same time , can facilitate the real change.

With all of these constituents and levels, the movement for creating schools that learn is, itself, a kind of crossroads. People come to it from a wide variety of circumstances and with only a few things in common. They all have a commitment to the children of their communities, they know that each community's future is its children. They know that schools need to change - and that change happens sometimes incrementally, and sometimes in big leaps, but it never happens without commitment from the people involved. Learners retain only that which they truly want to learn.

(Schools That Learn, p. 18). The following Figure 6 is a diagram of community elements.

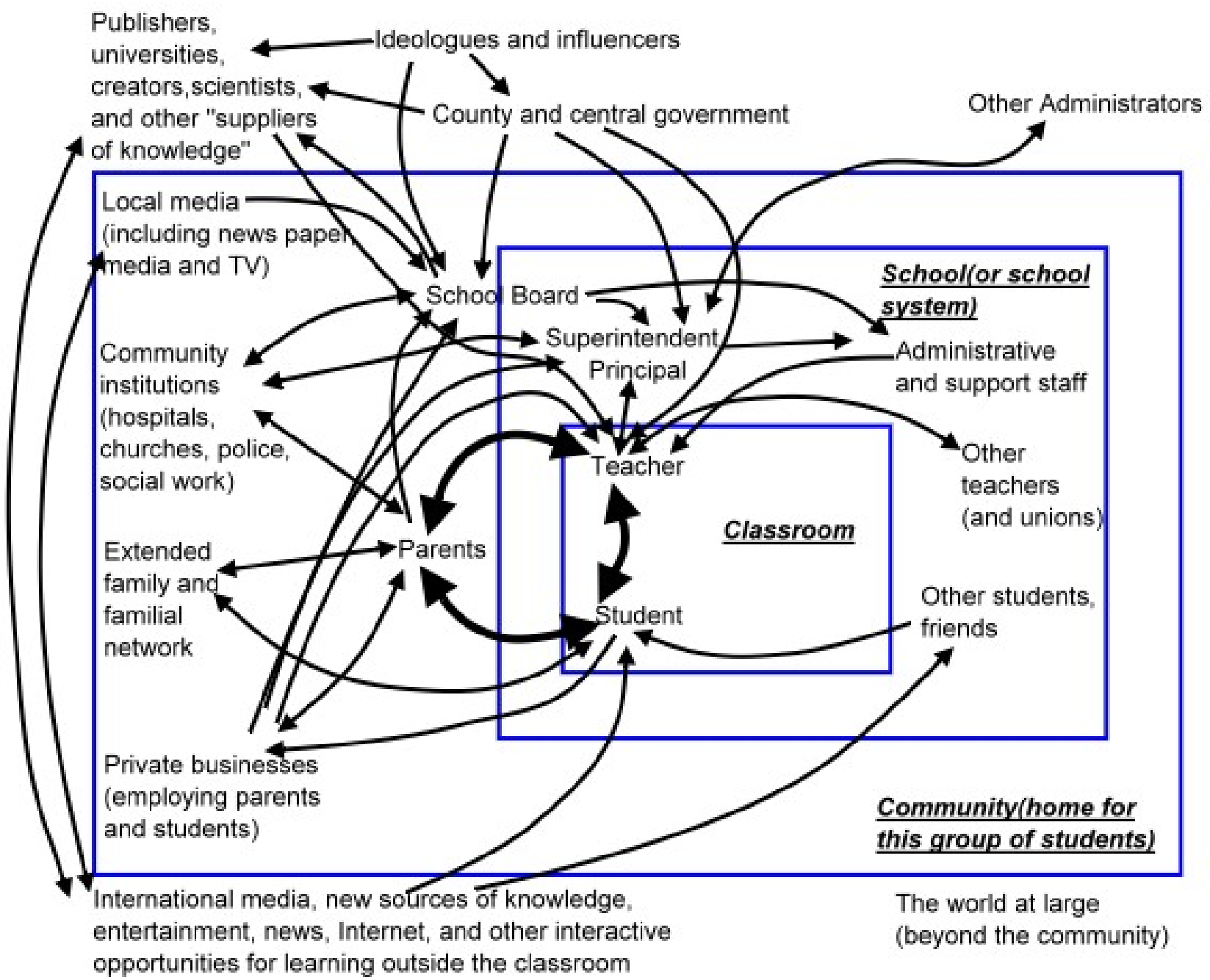

Figure 6 Community Elements Diagram 


\section{- The learning classroom}

The learning classroom is an arena where students get what is given by their teachers. Parents are not directly involved yet they can offer whatever help they can whenever necessary. The three parties - students, teachers and parents - are all contributors as well as dependents of the learning classroom.

1 Teachers themselves are practitioners of the philosophy of lifelong learning. It is called for that they keep up the momentum to learn more about the teaching skills and to go deeper and wider into their own special field. Also, they play the role of a guardian angel to their students. Schools are expected to provide teachers with a specific career ladder and a sense of job security.

2 Students are not supposed to be passive receptacles of knowledge. They are expected to play a more active role in knowledge assimilation and in school development. They are the only ones involved in all these three sectors of learning-oriented system.

3 Parents' enthusiastic involvement is a great help for teachers who aspire to achieve in their classroom activities.

As can be seen from what is discussed above, a student's intellectual development depends heavily upon how willing the adults involved in all these three sectors are to elevate themselves intellectually.

\section{The learning school}

A school is supposed to be a place what sufficient amounts of quality instruction is provided and where the teaching staff has access to opportunities of self-development in all related areas. The following is a short list of personnel who have most influence on an established regular school:

1. Superintendent: As an executive leader of an operating school, a superintendent can hope to set an example of being highly efficient, being more reform-minded and being more enthusiastic about running the learning school.

2. Principal and heads of various administrative departments: These people may sometimes feel that they do not have much room lying between the lower layer of teachers and parents and that of a higher-level government agency. In fact, principals and the administrative department heads play a vital part of lubricating the whole study-oriented machine. They do not just rule from above. They act as a leader of the adventure tour group and most important, they supervise and are responsible for the success of the whole learning process.

3. Officials supervising the school district and representatives from the local community: They are generally deemed as general overseers, regulators and policy-makers. If they stress the whole operation of the system on the basis of organizational learning, they are sure to have an enormous influence on the school in question and on any people involved in its operation.

\section{The learning community}

As represented in Figure 6, a community is a convergent entity of all kinds of complex elements. Of course what is sketched of a community by any individual is more or less different from what is done by the next. However, complexity is absolutely the thing that is generally acknowledged to characterizes a community. Success of reform in one community often activate a chain of reactions and bring about the same success stories in another. Two types of people have to be taken into account here:

\section{1. community members:}

Technological advancement has reached far and wide into every corner of our society with the introduction of the Internet, members in all sectors of a community local representatives, businessmen, social workers and educators all have the feeling that they are actual getting more and more interdependent. They feel strongly that there ought to be a constant and consistent 
link between the classroom and the school and the community. In order to prepare intellectually well-developed kids, more grown-ups are willing to involve themselves in the work of bringing the three corner-stones of the classroom, the school and the community closer together.

2. Lifelong learners: Traditionally, the school is where knowledge is absorbed. Then whatever knowledge one learns at school is to be applied to situations arising in one's adult life. A studyoriented community works hand in hand with a local school to create a learning environment which caters to different needs of different age groups. It also poses as a contrast to what education is conducted in its traditional ways.

\section{THE PROCESS OF EXTENDING CREATIVE LEARNING}

Our school tries to propagate the idea of creative learning based on the conception that both a closer link between the classroom, the school and the community and a more substantial exchange of resources among the three are where the trend is going and at the same time the most important contributing factor to any community member's life learning habit. The following is what we have done and constantly do:

1. The establishment of a reader database and a network of contacts: As the school library is open conditionally to the local community. Its readership, therefore, consists of the teaching staff, the students, retired teachers and members of the school board. A reader database is set up, by entering all categories of information: student serial numbers, class serial numbers, grades, student names, parents’ names, home phone numbers, home addresses, occupations, professional skills, choices of volunteer work. To make it a complete applicable and functional form, a meeting with heads from different school department as its participants should be held as preparation work for its content design. In addition, the principal, department heads, members of the school board and representatives from the community are expected to get into more interaction with one another, to attend local community conferences and to give an ear to ideas and opinions offered by local community members in order that an easier, smoother, more harmonious and more mutual beneficial relationship can be established and maintained. The school library can hold regular book-reading sessions or book exhibitions. The school counseling office can support activities such as parent or child talks, sessions and lectures focused on college admission and college department introduction. The department of student affairs are welcome to organize on-campus parties or fairs, athletic meets or thank-you-sir farewell parties. With activities like these, the school reaches out and a bridge of greater communication is built and a closer network of contacts is established.

\section{Encouraging greater involvement of book-reading clubs among teaching faculty,} administrative staff, students and parents: It is generally agreed that an uplifting spiritual life of each individual contributes to a more harmonious society. Also, a smooth-running society is a generator that powers the huge machine of society. A resilient mind capable of any internal improvement begin with the willingness of an individual to remove as much as possible the weed of selfishness from his mind. This way, there can be hope for a society teeming with sympathy and compassion. Among the chief cost-efficient results are: individuals are encouraged to invest more time in reading books with a purpose or books that are inspiring. Individuals are also observed to get more involved in experience sharing or discussions of various kinds, to broaden their world of knowledge and to get to know each other better. Starting from year 2000, the central government set the policy of “ one class, one book-reading club”. Annually, one or sometimes more than one training camp of book-reading club leaders is organized by the school library. A good-quality books exhibition is also on the agenda of the school anniversary. The school principal also takes the leading role in the participation in the book-reading club's activities and the by-product of a better coordination among the administrative is often the result. The Taichung based office of the Ministry of Education also requested National Tainan Girls' Senior High School to hold network book-reading club for all senior high school in Taiwan. In 
Keelung, we have promote this business for 3 years and attend this club’s students increases with rate of $30 \%$ every year.

\section{Holding regular contests in web page design, book reading report and evaluation of}

reading club performance: The purposes of holding contests before school's anniversary are evaluation of promoting activities' performance. We also encourage outstanding students to attend contests sponsored by outside of school. In 2004, one team of students obtained the second place of national web page design contest. At least one student gets award from attending national book-reading report contest every year. We offered reward for counselor and students who get the award from attending contest, it makes them more confidence and good for promoting information literacy and book-reading.

\section{Compiling and editing CLE training materials and training seed teachers and students to} learn to operate computer software tools: Dr. David Lin got the Ph.d. degree from Texas University in Austin, his major is system dynamics. CLE has popularized over ten years in America and Canada.system thinking philosophy in The Fifth Discipline is developed to be System Dynamics by Dr. Jay W. Forester, his student Peter M. Senge developed the theory of system thinking and the learning organization. He thinks the innovation in organization, it is hard to achieve breakthrough, it is not like engineer, science or art because it is difficult to experiment.. For this reason, he focused his research on a simulated "organizational study laboratory" created by a systematic dynamic computer. (primary school and high school students can download free software of systematic thinking with the name Vensim". It enables them to make various attempts at every possible conceptual ideas, strategies, situational changes and all sorts of possible combinations. It is hoped that students' dynamic logical thinking and creativity are strengthened through the process. Equipped with such an understanding, three seed teachers from our school began to work on the compiling and editing of teaching materials. The following are the steps they took:

(1) Devoting sufficient quantities of time on the reading of the two books: Schools That Learn and The Fifth Discipline. Brain-storming discussions were held regularly to substantiate the concept of a systematic thinking process.

(2) Working on more efficient ways to enhance information processing capability. Prof. Hsiao NaiChi was invited to deliver a lecture at our school.

(3) Teaching and facilitating the application of the software of systematic thinking process Vensim and the setting up of modules.

a. A basic introduction of systematic dynamics.

b. Setting up modules.

(4) Five instances of systematic thinking process presented

a. The story of a coffee cup,

b. The story about population growth and population explosion,

c. The story about population growth, population explosion and population collapse,

d. The story about the food-chain,

e. The story about communicable diseases.

(5) In-depth reading and discussions on "The U.S.A Math Textbooks for Senior High School Students Based on Dynamic Thinking Process".

(6) Compiling and editing of teaching materials and modifications of teaching methods and materials.

- Linear behavior.

- Quadratic behavior.,

- Nonlinear behavior.

- Exponential behavior.

- Oscillatory behavior.. 
- Convergent logistic behavior.

- Differential equations.

\section{Issuing E-newsletters}

Our school has accumulated two years' experience of issuing e-newsletters. It is our hope that a better-quality, more versatile community e-newsletter will emerge if and when all 13 local academic and vocational senior high schools can work together toward the goal. There sure will be lots of benefits involved, less manpower and greater mutual exchanges among others. More important, it can serve as a platform on which creative issues of special interest can be discussed and the exchange and marketing of issue researches can be made known and made possible. The baffling problem is that an advisory team which is in charge of all academic and vocational senior high schools nationwide already has its own e-newsletter. Insufficient funding has also cornered and stopped the future publication of our e-newsletters. For the time being, all creative-thinking issues and issue-related researches are channeled into the e-newsletters constructed by the aforementioned advisory team. Nevertheless, we are still in firm belief that from a long-term viewpoint, a community-level localized e-newsletter is what is needed to serve as a tool that helps boost the idea of marketing creative learning exchanges, provide an incentive to construct a life-learning environment and improve local citizens' capability to confront and handle problems.

\section{Prioritizing problems left unsolved and defining specific prospects for every individual school}

How to make its specific features and prospects appealing to potential recruits has always been a goal set by each school. There are also the challenges of how to elevate students' academic performance level and enhance a school's public image. In addition to the primary mission of getting as many kids to colleges and universities as possible, we insist that more emphasis be placed on students' social and life skills. Furthermore, we encourage all elements of the school, whether a teaching/administrative staff member or a student, to read books outside the classroom to learn how to learn, to hone their problem-solving ability. For instance, our school geographically fronts the Tien-Liao River and faces Mt. Hung-Tan in the distance. We have long been harboring an ambitious plan: to make a detailed, in-depth investigation into their specific ecosystems. Considering the limited resources (instruments and personnel armed with expertise in these fields, for example), enthusiastic teachers and students from our school teamed up with professionals, scholars and other resources available from outside. (Note: most of these professionals and scholars are from local City Environment Bureau, National Keelung Marine High School and National Ocean University). The teamwork based on systematic-thinking modes and the applications of the PC software Vensim has its reward of a complete analytical research report and a set of valuable recommendations as a reference for the implementation of environmental protection work. During and after the process, those who were involved in the project all felt that they grew up in their special fields and learned more in the areas of mutual communication, coordination, systematic thinking approaches, problem-pinpointing, data collecting, data assessing and analyzing, and thereby increased capability to solve problems.

\section{OBSTACLES TO BE CONQUERED AND RECOMMENDATIONS}

In Taiwan, all the senior high schools and vocation high schools meet some obstacles in promoting creative learning exchange. So far, we have three obstacles to be conquered.

\section{- Lack of qualified and certified teachers:}

Courses on systematic thinking process opened and going on at certain colleges and universities are mostly at their initial trial stage. Furthermore, as a result of an acute lack of qualified and certified teachers, the systematic thinking process I not extensively applied to the learning process off other disciplines of science.

\section{- Lack of pedagogical approaches:}


Due to an obvious shortage of capable teachers, translated materials that are sufficiently professional and suit the need of the students here are too few in variety and too small in quantity.

\section{- Money problems:}

The project is still in its initial, groping-its-way-along phase, with no agency or bureau of any appropriate authority serving as its supervisor, it suffered from a tight budget, which in turn had its grave impact upon the matters of policymaking or performance evaluating. The limited financial resources available usually came as a response to a separate, specific case of research project. Often, and sad to say, we had to rely on the meager appropriation from the school yearly budget.

To confront and conquer the barriers mentioned above, we have come up with the following recommendation:

- Creative thinking process be incorporated into the design and development of school curricula. Extracurricular clubs with creative thinking process as their core ideas can be started, their performance and results evaluated before finally being integrated into the whole school curriculum.

- Institutes be created at local and national levels.

Such institutes, with promotion of creative thinking process as one of its vital roles, are supposed to hold seminars on a regular basis, to carry out promotion programs and thereby evaluate their performance, to construct web pages and issue e-newsletters, and to hold contests and publish journals.

- A sufficient amount of funding be provided.

To get the necessary funding, the school in charge has to tender:

- Short-term plans regarding seminars on creative-thinking process and workshops of seed-teachers training programs,

- Mid-term plans concerning class-teaching demonstrations and related contests,

- Long-term plans with focuses on a better pool of teachers, amore definite outline of curricula and a more extensive application in colleges and universities as a selective or required course.

\section{CONCLUSION}

The eventual success will be laid on the groundwork of selfless cooperation on the part of the administrative staff, the teaching faculty, the studnet6 body and the students' parents. To make the whole project possible, any and every possible situation has to be taken into account and incentives big and small have to be created. It is something that requires contribution made not only by individuals but also by all involved. The central idea of teaching students to learn how to learn and creative thinking approaches should always be the consistent goal because it is this ultimate capability that arms them in the face of problems and helps with the problem-solving. It is estimated that a full $25 \%$ of an individual's resources is dedicated to lea4rning in preparation for the challenges in life in a changing world. Such a huge stake of one's resources is absolutely an important and worthwhile investment rather than a meaningless and purposeless waste.

\section{References}

Peter M. Senge, Nelda Cambron-McCabe, Timothy Lucas, Bryan Smith, Janis Dutton and Art Kleiner. (2000). Schools That Learn: A Fifth Discipline Fieldbook for Educators, Parents, and Everyone Who Cares About Education.

Peter M. Senge. (1994). The Fifth Discipline: The Art and Practice of The Learning Organization.

Vensim 5 Users Guide. Ventana System Inc.http://www.vensim.com 
Reproduced with permission of the copyright owner. Further reproduction prohibited without permission. 